\title{
Bioactive Compounds Produced by Strain of
}

\section{Penicillium sp.}

\author{
M. Shaaban \\ Nat. Comp. Dept., Division \\ of Pharm. Indust., National \\ Research Centre, Dokki- \\ Cairo, Egypt
}

\author{
M. G. Elfedawy \\ Chem. Dept., Fac. of Sci., \\ Mansoura University \\ Mansoura, Egypt
}

\author{
G. Elhady Sohsah \\ Chem. Dept., Fac. of Sci., \\ Mansoura University \\ Mansoura, Egypt
}

\author{
M. Abdel-Mogib \\ Chem. Dept., Fac. of Sci., \\ Mansoura University \\ Mansoura, Egypt
}

\author{
M. Magdy El-Metwally \\ Bot. and Microbiol. Dept., \\ Fac. of Sci., Damanhour \\ University, Damanhour, \\ Egypt
}

\begin{abstract}
During our search for bioactive compounds from fungi, the terrestrial Penicilliumsp.KH Link 1809 isolate KHMM was fermented on large scale using solid rice medium. After harvesting, working up and purification of the afforded extract using different chromatographic techniques, the bioactive metabolites viridicatol (1) and kojic acid (2) were isolated. The chemical structures of $\mathbf{1}$ and $\mathbf{2}$ were confirmed by extensive 1D and 2D NMR and mass measurements, and by comparison with literature data. The antimicrobial activity of the strain extract was studied using a panel of pathogenic microorganisms.
\end{abstract}

Keywords: Penicillium sp., Bioactive metabolites, Biological activity, Taxonomy.

\section{INTRODUCTION}

Fungi represent strongly rich producers of potent bioactive secondary metabolites [1], acting as antibiotics [2], antimycotics [3], antiviral [4], and anticancer agents [5], or are pharmacologically active in other ways [6]. The genus of Penicillium is one of the most prolific sources of bioactive drugs and large range of compounds including polyketides, alkaloids, terpenoids, and peptides, including a large huge number of cytotoxic compounds [7,8]. Based on the taxonomical characterization, the genus Penicillium is representing one of the most complex of the fungal world, with 225 species approximately and a continued discovery of new species [9]. Traditionally, species in the genus Penicillium, which are fundamentally saprophytic and ubiquitous, have been regarded as a fruitful investigational ground for the finding of novel bioactive compounds, leading to the discovery of blockbuster drugs, such as penicillin [10] and the anticholesterolemic agent compactin [11], miscellaneous antitumor products [12], and mycotoxins contaminating food [13]. Most of these fundamental studies were carried out on strainsfrom soil and food commodities [14].However, the search for further new bioactive compounds from fungi isolated from untouched habitats is still strongly recommended and needed to overcome the huge gap between the currently inadequate drugs and needed new ones to treat the recently discovered diseases $[15,16]$.

In our continual program for searching of bioactive compounds from the genus of Penicillium, the Penicilliumsp. KHMM isolated from Egyptian habitats [17], has been applied to biological and chemical assays, announcing potent antimicrobial activity against different pathogenic microorganism, mainly Gram positive and Gram negative bacteria, and yeast (Table 1). Chemically, the strain extract showed several middle-polar zones during TLC visualized by UV light and spraying with anisaldehyde/sulphuric acid. A large scale fermentation of the strain on rice-solid medium followed by working up and purification using a series of different chromatographic techniques afforded the bioactive compounds viridicatol (1) and kojic acid (2). The chemical structures of the isolated compounds were confirmed by extensive 1D and 2D NMR and ESI HR mass measurements, and by comparison with literature data. The antimicrobial activity of the strain was studied using a set of microorganisms. The isolation and taxonomical characterization of the fungal strain is reported as well.

\section{EXPERIMENTAL}

\subsection{General}

NMR spectra $\left({ }^{1} \mathrm{H}\right.$ NMR, ${ }^{13} \mathrm{C}$ NMR, DEPT, COSY, HMQC and HMBC) were measured on Bruker Avance DRX 500 and DRX $600 \mathrm{MHz}$ 
spectrometers [Q] using standard pulse sequences and referenced to residual solvent signals. HR-EIMS was determined using GCT Premier Spectrometer. The ultraviolet and visible (UV-Vis) spectra were measured on Spectro UV-Vis Double Beam PC8 scanning auto Cell UVD-3200, LABOMED, INC [Q].Column chromatography was carried out on silica gel $60(0.040-0.063 \mathrm{~mm}$, Merck [Q]) and Sephadex LH-20 as the stationary phases. Preparative TLC $(0.5 \mathrm{~mm}$ thick $)$ and analytical TLC were performed with pre-coated Merck silica gel $60 \mathrm{PF}_{254+366 .} R_{\mathrm{f}}$ values and Visualisation of chromatograms was carried out under UV light ( 254 and $366 \mathrm{~nm}$ ) and further by spraying withanisaldehyde/sulphuric acid followed by heating.

\subsection{Isolation and Taxonomy of the producing strain}

The fungus Penicillium sp. KHMM was isolated from a soil sample collected from Tag elezz agricultural research station, Dakahyia region, Egypt, at a depth of $5 \mathrm{~cm}$ under sterile conditions. The fungus was isolated by conventional dilution plate technique [18]. One gram of the sample was suspended in $10 \mathrm{~mL}$ of sterilized water and shaked for $2 \mathrm{~h}$. The sediments were then left to settle down for few minutes. The supernatant was then applied to successive dilution up to $10^{-6}$. An aliquot $(1 \mathrm{~mL})$ of the afforded suspension was spread over CzapekDox agar medium $\left(\mathrm{gL}^{-1}: 30\right.$ sucrose, $3 \mathrm{NaNO}_{3}, 1$ $\mathrm{K}_{2} \mathrm{HPO}_{4}, 0.5 \mathrm{KCl}, 0.5 \mathrm{MgSO}_{4}, 0.01 \mathrm{FeSO}_{4}, 20$ agaragar, and distilled water ( $1 \mathrm{~L})$ at $\mathrm{pH}$ 7.3]), and incubated at $28^{\circ} \mathrm{C}$ for 14 days, the growing colonies isolated in slants of the same medium and stored in refrigerator at $4^{\circ} \mathrm{C}$ until use.

On Czapeck-Dox agar medium, Colonies of the fungal isolate showed vegetative mycelium abundant, colorless or pale- or brightly-colored, Colonies low to moderately deep, plane to very faintly sulcate; margins low, narrow to wide (1-5 $\mathrm{mm})$, sporulation highly dense, conidia dull to greyish green exudate clear to almost a hazy yellow, sometimes absent; soluble pigment mostly yellowish orange.

In micromorphology, conidiophores typically borne from green mycelia embedded in medium, stipes mostly hyaline but sometimes green, mostly biverticillate, infrequently terverticillate, monoverticillate side branches sometimes present; Stipes very short to very long, typically rough, a minor proportion smooth to finely rough. Branches two when present, etulae 3-5 per stipe, Phialides ampulliform, 6-9 per etula, Conidia smooth, globose to subglobose.According to theses cultural and morphological features, and according to Raper and Thom (1949) [19], the terrestrial fungal strain KHMM is belonging to Penicillium genus. An authentic isolate of the strain is deposited at collection of Dr M. M. El Metwally, Botany and Microbiology Department, Faculty of Science, Damanhour University, Egypt.

Fermentation, working up and isolation

The Penicillium sp. KHMM was inoculated from well grown agar plates with dark green sporulating colonies into $0.1 \mathrm{~L}$ sterilized glass bottles each containing modified rice medium composition: $8 \mathrm{~g}$ commercial rice; $10 \mathrm{~mL}$ distilled water. The bottles were incubated for 15 days at $30^{\circ} \mathrm{C}$.

After harvesting, $50 \mathrm{~mL}$ of 1:1 $\mathrm{DCM} / \mathrm{MeOH}$ was added to each bottle, followed by aggressive shaking for two hrs, and the afforded organic extract was decanted, filtered, and then concentrated in vacuo till dryness, affording ( $9.5 \mathrm{~g}$ ) as brown crude extract. The crude extract was then suspended in water and applied to successive extraction in separating funnel $(0.5 \mathrm{~L})$, starting with pet. ether, dichloromethane (DCM), ethyl acetate and nbutanol, consequently. The corresponding fractionated extracts were concentrated to dryness affording KH1 (0.3 g), KH2 (0.4 g), KH3 (3.2 g) and $\mathrm{KH} 4(2.4 \mathrm{~g})$, respectively, as reddish brown fractions. Fractions KH1 and KH2 showed undesired components according to TLC visualization and excluded.

The ethyl acetate fraction $\mathrm{KH} 3 \quad(3.2 \mathrm{~g})$ was subjected to purification on silica gel column $(3 \times$ $60 \mathrm{~cm})$, eluted with DCM-MeOH gradient $(0.5 \mathrm{~L}$ DCM/3\% MeOH [97:3], 0.5 L DCM-MeOH [95:5], 0.5 L DCM-MeOH [90:10], 0.5 L DCM-MeOH [80:20] , 0.5 L DCM-MeOH [1:1], 0.2 L MeOH. Three fractions were afforded according to TLC monitoring: FI (3.2 g), FII (1.2 g), FIII (0.3 g). Fraction FI is mostly containing fatsand phthalate and discarded. Purification of fraction FII using Sephadex LH-20 (MeOH), followed by silica gel column eluted by DCM-MeOH and finally with Sephadex LH-20 (MeOH) afforded a colorless solid of viridicatol $(1,5 \mathrm{mg})$. As the same for the ethyl acetate fraction, purification of the n-butanol fraction KH4 $(2.4 \mathrm{~g})$ using silica gel column followed by Sephadex LH-20 afforded a colourless solid of kojic acid (2, $8 \mathrm{mg})$.

\section{Viridicatol (1):}

Colorless solid, UV absorbing showing brown coloration on spraying with anisaldehyde/sulphuric acid: $\quad R_{\mathrm{f}}=0.45 \quad(\mathrm{DCM} / 7 \% \quad \mathrm{MeOH}) .{ }^{1} \mathrm{H} \quad \mathrm{NMR}$ $\left(\mathrm{CD}_{3} \mathrm{OD}, 500 \mathrm{MHz}\right)$ and ${ }^{13} \mathrm{C} \mathrm{NMR}\left(\mathrm{CD}_{3} \mathrm{OD}, 125\right.$ $\mathrm{MHz}$ ) see Table 1.

(+)-ESI MS: $\mathrm{m} / \mathrm{z}(\%) 276\left([\mathrm{M}+\mathrm{Na}]^{+}, 100\right), 529$ $\left([2 \mathrm{M}+\mathrm{Na}]^{+}, 70\right)$; (-)-ESI MS: $m / z(\%) 252\left([\mathrm{M}-\mathrm{H}]^{-}\right.$, $100)$.

Kojic acid (2):

Colorless solid, UV absorbing showing no color staining on spraying with anisaldehyde/sulphuric acid. $R_{\mathrm{f}}=0.22(\mathrm{DCM} / 10 \% \mathrm{MeOH}) .{ }^{1} \mathrm{HNMR}$ (DMSO-d6, $500 \mathrm{MHz}$ ): $\delta 8.99$ (br s, $1 \mathrm{H}, \mathrm{OH}$ ), 5.69 (br s, 1H, OH), 7.97 (d, 1H, J=7.97, H-2), 6.34 (s, 1H, H-5), 4.28 (s, 2H, H2-7). ${ }^{13} \mathrm{CNMR}$ (DMSO-d6, $125 \mathrm{MHz}): \delta 174.2\left(\mathrm{C}_{\mathrm{q}^{-}}-4\right), 168.2\left(\mathrm{C}_{\mathrm{q}^{-}}-6\right), 153.0\left(\mathrm{C}_{\mathrm{q}^{-}}\right.$ 3), $138.9(\mathrm{CH}-2), 110.0$ (CH-5), $59.7\left(\mathrm{CH}_{2}-7\right)$.

\section{Antimicrobial Assay Using Agar Diffusion Test}

Antimicrobial activity testing of the crude extract of the fungal isolate $\mathrm{KH}$ was carried out against a set of microorganisms using the agar diffusion technique. Paper-disk diffusion assay [20] with 
some modifications has been followed to measure the antimicrobial activity. $20 \mathrm{~mL}$ of medium seeded with test organism were poured into $9 \mathrm{~cm}$ sterile Petri dishes. After solidification, the paper disks were placed on inoculated agar plates and allowed to diffuse the loaded substances into refrigerator at $4{ }^{\circ} \mathrm{C}$ for $2 \mathrm{~h}$. The plates were incubated for $24 \mathrm{~h}$ at $35^{\circ} \mathrm{C}$. Both bacteria and yeasts were grown on nutrient agar medium: $3 \mathrm{~g} / \mathrm{L}$ beef extract, $10 \mathrm{~g} / \mathrm{L}$ peptone, and $20 \mathrm{~g} / \mathrm{L}$ agar. The $\mathrm{pH}$ was adjusted to 7.2. Fungal strain was grown on potato dextrose agar medium (g/L): Potato extract, 4; Dextrose, 20; Agar No. 1, 15 (pH 6). The samples were dissolved in $\mathrm{DCM} / 10 \% \mathrm{MeOH}$. Aliquots of $50 \mu \mathrm{L}(=50 \mu \mathrm{g})$ were soaked on filter paper discs $(9 \mathrm{~mm})$ and dried at room temperature under sterilized conditions. The paper discs were placed on inoculated agar plats and incubated for $24 \mathrm{~h}$ at $37^{\circ} \mathrm{C}$ for bacteria and $48 \mathrm{~h}$ $\left(30^{\circ} \mathrm{C}\right)$ for the fungi. After incubation, the diameters of inhibition zones were measured with a wide panel of test microorganisms comprising Gram positive bacteria (Bacillus subtilis ATCC6633 and Staphylococcus aureus ATCC6538-P), Gram negative bacteria (Pseudomonas areuginosa ATCC 27853), yeast (Candida albicans ATCC 10231, and the fungus Aspergillus niger NRRL A-326.

\section{RESULTS AND DISCUSSIONS}

\subsection{Fermentation and Structure Elucidation}

The Penicillium sp. KH Link 1809 was cultured on rice solid medium. Biologically, the afforded extract of the strain exhibited high activity against Gram positive, Gram negative bacteria, and yeast, namely: Bacillus subtilis ATCC6633, Staphylococcus aureus ATCC6538-P), Pseudomonas areuginosa ATCC 27853, and Candida albicans ATCC 10231 (Table 1). In the chemical screening monitored by TLC, the fungal extract exhibited two major UV absorbing bands with a narrow polarity range, one of them exhibited a brown staining with anisaldehyde/sulphuric acid. Some other unpolar bands were detected as violet-blue on spraying with the same reagent, which might be attributed to some fats, phthalates or sterols. Separation of the strain produced middle polar bioactive metabolites using a series of chromatographic techniques (see experimental section) afforded Viridicatol (1) and kojic acid (2).

\section{Viridicatol (1)}

As Colorless solid, compound $\mathbf{1}$ was obtained showing UV absorbance at $254 \mathrm{~nm}$ during TLC, which stained as brown on spraying with anisaldehyde/sulphuric acid. The molecular weight of 1 was deduced as 253 Dalton according to ESI MS modes, such that two pseudo ion peaks were exhibited at $\mathrm{m} / z 276[\mathrm{M}+\mathrm{Na}]$ and $529[2 \mathrm{M}+\mathrm{Na}]$ were exhibited, and one ion peak was visible at $\mathrm{m} / \mathrm{z}$ $252[\mathrm{M}-\mathrm{H}]$ in the ESI negative mode. HRESI MS of 1 revealed the corresponding molecular formula as $\mathrm{C}_{15} \mathrm{H}_{11} \mathrm{NO}_{3}$, bearing eleven double bond equivalents.

Based on the ${ }^{1} \mathrm{H},{ }^{13} \mathrm{C}$ and HMQC NMR spectra $\left(\mathrm{CD}_{3} \mathrm{OD}\right)$ (Table 2), the numbers of hydrogen and carbon atoms were in agreement with the molecular formula. Based on the ${ }^{1} \mathrm{H}$ NMR spectrum, $\mathrm{H}, \mathrm{H}$ COSY experiment, and coupling constants, eight proton signals $(\delta 8.15,7.36[2 \mathrm{H}], 7.34,7.26,6.88$, $6.83,6.82$ ), were observed in the aromatic region, indicating the presence for ortho- and metadisubstituted benzene systems. In the ${ }^{13} \mathrm{C}$ NMR spectrum and HMQC experiment, one carbonyl carbon signal $(\delta 159.1)$ and $14 s p^{2}$ carbon signals, including eight methine signals $(\delta 129.1,124.9$, $122.4,121.6,120.7,116.5,115.0,114.5)$, were observed. According to the above data, followed by study the structure using HMBC experiment (Fig.1), the structure of the title alkaloid was assigned as viridicatol (1) [21,22]. Viridicatol was isolated previously along with viridicatin from a strain of $P$. viridicatin [23]. Functionalized 4-arylquinolin$2(1 \mathrm{H})$-ones constitute generally, a valuable class of biologically active molecules, including several fungal metabolites such as viridicatin [24] and 3-Omethylviridicatin [25]. Viridicatol was reported to show cytotoxicity toward KB, KBv200, A549, hepG2, MCF7, K562, SMMC7721, and SGC7901 tumor cell lines with $\mathrm{IC}_{50}$ values of $25.0,16.5,60.0$, $85.0,45.0,25.0,80.2$, and $80.0 \mathrm{~g} / \mathrm{mL}$, respectively.

\section{Kojic acid (2)}

As polar Colorless solid, exhibiting UV absorbance at $254 \mathrm{~nm}$ during TLC, compound 2 was obtained, which showed no color staining on spraying with anisaldehyde/sulphuric acid. Based on EI MS, the molecular weight of $\mathbf{2}$ was deduced as 142 Daltons, and the corresponding molecular formula was established by EI HRMS as $\mathrm{C}_{6} \mathrm{H}_{6} \mathrm{O}_{4}$, containing four double bond equivalents. The ${ }^{1} \mathrm{H}$ NMR spectrum (DMSO- $d_{6}$ ) of $\mathbf{2}$ displayed two broad signals at $\delta$ 8.99 and $\delta 5.69$, which could be attributed to exchangeable protons of phenolic and aliphatic hydroxyl groups, respectively. Two further proton singlets each of $1 \mathrm{H}$ were visible at $\delta 7.97$ and 6.34 , in addition to anoxy-methylene signal as singlet at 84.28. Based on the ${ }^{13} \mathrm{C}$ and APT NMR spectra, three quaternary $s p^{2}$ carbon signals were displayed at $\delta 174.2,168.3$ and 153.0, representing a lactone carbonyl ( $\delta 174.2)$, oxygenated $s p^{2}$ carbon (168.3) in $\beta$-position with respect to a lactone carbonyl, and phenolic one $(\delta 153.0)$. Two $s p^{2}$ methine carbons were exhibited at $\delta 138.9$, and 110.0 , along with an oxy-methylene carbon $(\delta 59.7)$ as well. Based on the revealed chromatographic features, spectroscopic data, and search in the corresponding data bases (AntiBase [1], Dictionary of Natural Products (DNP) [26], and Scifinder [27], compound 2 was confirmed as kojic acid. Biologically, kojic acid is showing high toxicity and high antibiotic activity against Gram-Positive and Gram negative bacteria, and antifungal properties [28]. Kojic acid is a wellknown as tyrosinase inhibitor, and hence it has been used as whitening or anti-hyperpigment agent because of its ability to suppress dermal-melanin production [29].

\subsection{Biological activity studies}

Antimicrobial activity testing of the stain extract of the terrestrial fungus Penicillium sp. KH Link 1809 
was carried out against five microorganisms using the agar diffusion technique. The extract showed high antimicrobial activity (50 $\mu$ g per disk) against Gram-positive bacteria (Bacillus subtilis ATCC6633 [27 mm], Staphylococcus aureus ATCC6538-P [26 mm]), Gram-negative bacteria (Pseudomonas aeruginosa ATCC $27853[31 \mathrm{~mm}]$ ), and Candida albicans ATCC 10231 [25 mm]. Nevertheless, the extract showed no activity against Aspergillus niger NRRL A-326. (Table 1)

\section{Acknowledgement}

The authors are thankful to Prof. Dr. N. Sewald (Organic and Bioorganic Chemistry, Faculty of Chemistry, Bielefeld University, Germany) and his research stuff for lab facilities, NMR and MS measurements and support. We thank Prof. Dr. M. Asker for the antimicrobial activity testing. This research work has been financed by the German Academic Exchange Service (DAAD) with funds from the German Federal Foreign Office in the frame of the Research Training Network "Novel<smiles>O=c1[nH]c2ccccc2c(-c2cccc(O)c2)c1O</smiles>

1
Cytotoxic Drugs from Extremophilic Actinomycetes" (ProjectID57166072).<smiles>O=c1cc(CO)occ1O</smiles>

2

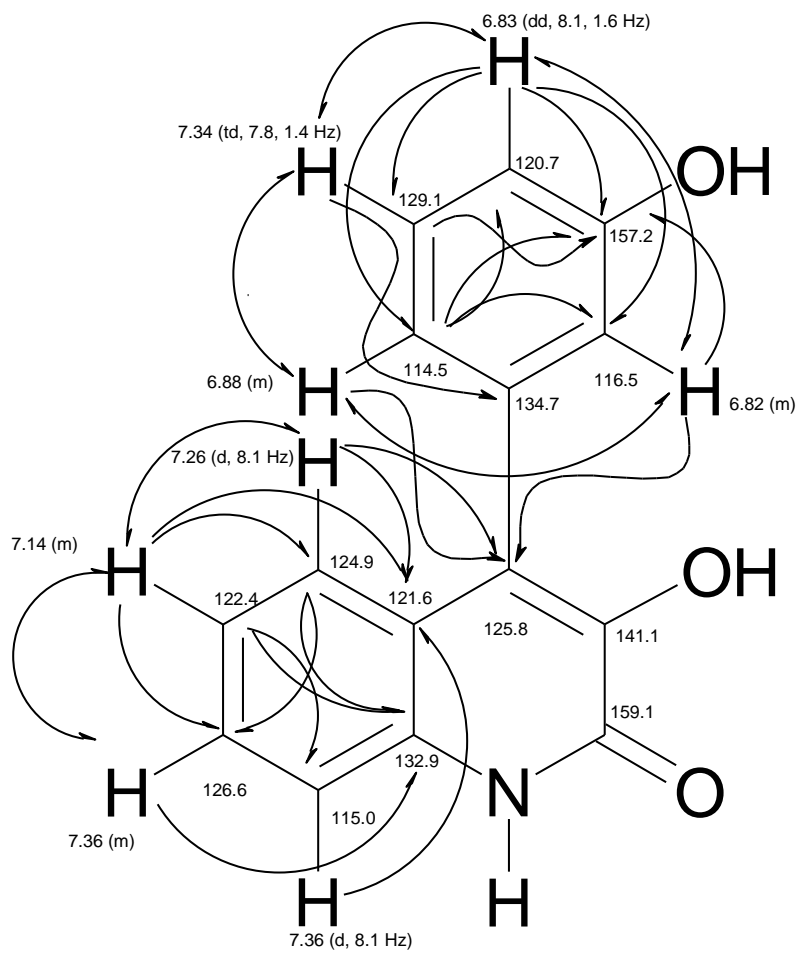

Fig.1: H,H COSY $(\leftrightarrow)$ and HMBC $(\rightarrow)$ correlations of Viridicatol (1)

Table 1: Antimicrobial activities of Penicillium sp.KHMM Link 1809 extract 
International Journal of Science and Engineering Applications

Volume 5 Issue 6, 2016, ISSN-2319-7560 (Online)

\begin{tabular}{lcccc}
\hline \multirow{2}{*}{ Extract } & \multicolumn{4}{c}{ Diameter of zone inhibition (mm) } \\
\cline { 2 - 5 } & P. aeruginosa & St. aureus & B. subtilis & C. albicans \\
\hline $\mathrm{KH}$ & 31 & 26 & 27 & 25 \\
\hline
\end{tabular}

Table 2: ${ }^{1} \mathrm{H}\left(\mathrm{CD}_{3} \mathrm{OD}, 500 \mathrm{MHz}\right)$ and ${ }^{13} \mathrm{C}\left(\mathrm{CD}_{3} \mathrm{OD}, 125 \mathrm{MHz}\right) \mathrm{NMR}$ data of Viridicatol (1)

\begin{tabular}{lll}
\hline Nr. & $\delta_{\mathrm{C}}$ & $\delta_{\mathrm{H}}$ \\
\hline 2 & 159.1 & \\
3 & 141.1 & \\
4 & 125.8 & \\
$4 \mathrm{a}$ & 121.6 & $8.15(\mathrm{dd}, 8.0,1.5)$ \\
5 & 124.9 & $7.26(\mathrm{~d}, 8.1)$ \\
6 & 122.4 & $7.14(\mathrm{~m})$ \\
7 & 126.6 & $7.36(\mathrm{~m})$ \\
8 & 115.0 & $7.36(\mathrm{~d}, 8.1)$ \\
$8 \mathrm{a}$ & 132.9 & \\
1 & 134.7 & \\
2 & & \\
3 & 116.5 & $6.82(\mathrm{~m})$ \\
4, & 157.2 & \\
5 & 120.7 & $6.83(\mathrm{dd}, 8.1,1.6)$ \\
6 & 129.1 & $7.34(\mathrm{td}, 7.8,1.4$ \\
\hline
\end{tabular}

\section{REFERENCES}

[1] Laatsch, H. (2014) AntiBase, A Data Base for Rapid Structural Determination of Microbial Natural Products, and annual updates, Wiley-VCH, Weinheim Germany.

[2] Butler, M. S. (2004) J. Nat. Prod. 67, 2141-2153.

[3] Brady, S. F., Clardy, J. (2000) J. Nat. Prod. 63, 1447-1448.

[4] Singh, S. B., Zink, D. L., Guan, Z., Collado, J., Pelaez, F., Felock, P.J., Hazuda, D. J. (2003) Helv. Chim. Acta 86, 3380-3385.

[5] Zhang, H. W., Song, Y. C., Tan,R. X. (2006) Nat. Prod. Rep.23, 753-771.

[6] Song,Y. C., Li,H., Ye,Y. H., Shan,C. Y., Yang,Y. M., Tan,R. X. (2004) FEMS Microbiol. Lett. 241, 6772.

[7] Bugni, T.S., Ireland, C.M. (2004) Nat. Prod. Rep. 21, 143-163

[8] Grovel, O., Kerzaon, I., Vansteelandt, M., Petit,K. E., Biard, J. F., Pouchus, Y. F. (2008) Planta Med 74 - SL99.

[9] Jens C. Frisvad. (2014) Taxonomy, chemodiversity, and chemoconsistency of Aspergillus, Penicillium, and Talaromyces species. Front Microbiol. 5, 773.

[10] Demain A.L., Elander R.P. (1999) The $\beta$-lactam antibiotics: Past, present, and future. Antonie Van Leeuwenhoek. 75, 5-19

[11] Chakravarti R., Sahai V. (2004) Compactin-A review. Appl. Microbiol. Biotechnol. 64, 618-624

[12] Nicoletti R., Ciavatta M.L., Buommino E., Tufano M.A. (2008) Antitumor extrolites produced by Penicillium species. Int. J. Biomed. Pharm. Sci. 2, 1-23

[13] Frisvad J.C., Smedsgaard J., Larsen T.O., Samson R.A. (2004) Mycotoxins, drugs and other extrolites produced by species in Penicillium subgenus Penicillium. Stud. Mycol. 49, $201-241$.

[14] Nicoletti, R., Trincone, A. (2016) Bioactive Compounds Produced by Strains of Penicillium and Talaromyces of Marine Origin.Mar Drugs. 14, 37; doi: 10.3390/md14020037.

[15] Strobel, G., Daisy, B. (2003) Microbiol. Mol. Biol. Rev. 67, 491-502.

[16] Hassan, A. E. H. A. (2007) Dissertation, University of Düsseldorf, Germany, 2007.

[17] Shaaban, M., El-Metwally, M. M., Laatsch, H. (2016) New Bioactive Metabolites from Penicillium purpurogenum MM. Zeitschrift Naturforsch. 71B, 287-296.

[18] Hayakawa, M. and Nonomura, H. (1987). Humic Acid-Vitamin Agar, a New Medium for the Selective Isolation of Soil Actinomycetes. J. Ferment. Technol. 65, 501-509.

[19] Raper, K. B.,Thom. (1949) A manual of Penicillium. Williams and Wilkins Baltimore. USA.

[20] Collins, C. H., Lyne, P. M. (1985) Microbiological methods, 5th ed. Butterworth and Co. Pub. Ltd., London and Toronto pp. 167-181.

[21] Mohammed, Y. S., Luckner,M. (1953) Tetrahedron Lett., 4, 1953. 
[22] Wei,M.Y., Yang,R.Y., Shao, C.-L., Wang, C.Y., Deng, D.S., She, Z.G., Lin, Y.C. (2011) Isolation, Structure Elucidation, Crystal Structure, and Biological Activity of a Marine Natural Alkaloid, Viridicatol. Chemistry of Natural Compounds, 47, 322-325.

[23] Ciegler,A., Kadis,S., Ajl, S. J. (1971) Microbial Toxins: A comprehensive Treatise; Fungal Toxins. Metabolites of Penicillium viridicatum and closely related species. Copyright by Academic press, INC 111 Fifth Avenue, New York 10003, Volume VI, 509.

[24] Luckner, M., Mothes, K. (1962) Tetrahedron Lett., 3, 1035.

[25] Austin, D. J., Myers,M. B. (1964) J. Chem. Soc., 1, 1197.

[26] Dictionary of Natural Products on CD-ROM, Chapman \& Hall Chemical Database, 2016.

[27] https://scifinder.cas.org/scifinder.

[28] Morton, H, Kocholaty, W., Junowiczkocholaty, R., Kelner, A. (1945) Toxicity, and Antibiotic Activity of Kojic Acid, Produced by Aspergillus Leuteo-Virescens 1, J. Bacteriol,.50 ,579-584.

[29] Uchida, R., Ishikawa, S., Tomoda, H. (2014) Inhibition of tyrosinase activity and melanine pigmentation by 2-hydroxytyrosol. Acta Pharmaceutica Sinica B., 4, 141-145. 